\title{
Synthesis of Acyclic $\beta$-Enaminones Through Reaction of Enones and Benzyl Azide
}

\author{
Amenson T. Gomes and Silvio Cunha \\ Universidade Federal da Bahia, Instituto de Química, Campus de Ondina, 40.170-290, Salvador - BA, Brasil \\ INCT de Energia e Meio Ambiente, Universidade Federal da Bahia Campus de Ondina, 40.170-290, Salvador - BA \\ *amenson@gmail.com
}

Keywords: enaminone, enone and benzyl azide

\section{INTRODUCTION}

The synthesis of enaminones is a theme of ongoing interest $^{1}$ because this class of compound is a versatile intermediate in organic synthesis ${ }^{2}$ as well as due to their biological activity. ${ }^{3}$

Enaminones are molecules with the conjugated system $\mathrm{N}-\mathrm{C}=\mathrm{C}-\mathrm{C}=\mathrm{O}$, and the amine and acyl group lead these compounds to have both reactive effects: electrophilic (blue) and nucleophilic (red).

Due to these electronic effects, enaminones are widely used as building blocks for the synthesis of natural products and heterocycles as indoles, carbazoles, quinolines among others.

Herein, we disclosure our results concerning the one-pot synthesis of enaminones through the reactions of acyclic $\beta$-aryl enones with benzyl azide, with emphasis on synthetic and mechanistic implications.

\section{RESULTS AND DISCUSSION}

To test the possibility of a direct route towards acyclic enaminones from acyclic $\beta$-aryl enones and benzyl azide, this late compound was reacted with enones in $\mathrm{CH}_{2} \mathrm{Cl}_{2}$, Scheme 1 .

In all reactions it was observed 1,2 phenyl migration instead of previous described 1,2 $\mathrm{H}$ migration ${ }^{4}$. The enaminones were obtained as mixture of cis-s-cis and trans-s-cis isomers of enones with benzyl azide, Table 1.

When enones with substituted ring were used, it was found one unexpected result with the enone containing the $p$-chlorobenzene group. Beyond the formation of the enaminone, there was one side reaction on methyl group, and with dimethoxiphenyl enone the reaction, produced only the trans-s-cis, isomer, Scheme 2.

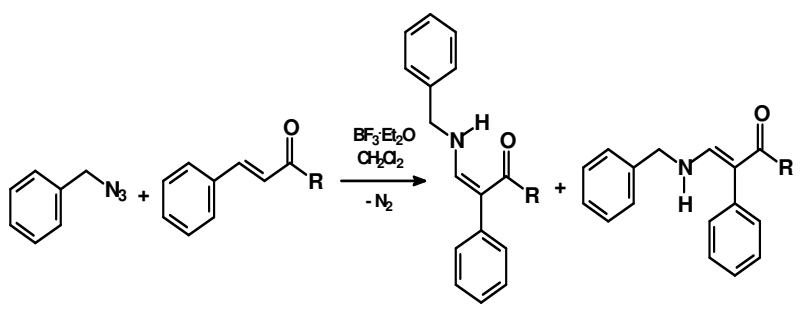

Scheme 1. Synthesis of enaminones
Table 1. Synthesis of enaminones

\begin{tabular}{|l|c|c|c|}
\hline \multicolumn{1}{|c|}{$\mathbf{R}$} & cis-s-cis $:$ trans-s-cis & (\%) & Time (h) \\
\hline$-\mathrm{CH}\left(\mathrm{CH}_{3}\right)$ & $1: 3$ & 96 & 72 \\
$-\mathrm{CH}_{3}$ & $3: 1$ & 44 & 72 \\
$-\mathrm{C}_{6} \mathrm{H}_{5}$ & $6: 1$ & 21 & 72 \\
$-\mathrm{CH}=\mathrm{CHPh}$ & $1: 2$ & 50 & 216 \\
\hline
\end{tabular}

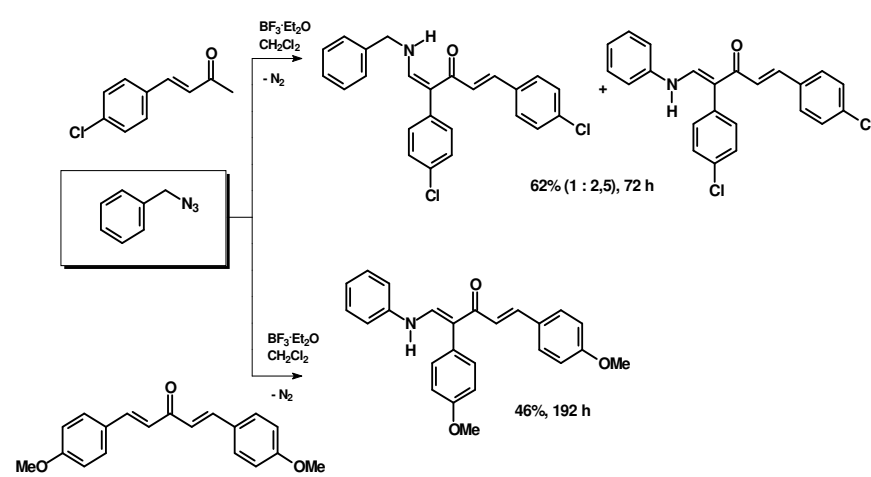

Scheme 2. Enaminones's synthesis with substituted ring

\section{CONCLUSION}

In conclusion, this study shows that the reaction of acyclic $\beta$-aryl enones and benzyl azide can be a practical synthetic route to densily substituted acyclic $\alpha$-aryl enaminones, being an alternative to the use of 1,3-diketones and amines to access this synthetically important class of compound.

\section{ACKNOWLEDGEMENTS}

\section{CNPQ FAPESB CAPES}

\section{REFERENCES}

1. Rafiee, E.; Joshaghani, M.; Eavani, S.; Rashidzadeh, S. Green Chem. 2008, 10, 982-989.

2. Ferraz, H. M.; Gonçalo, E. R. S. Quim. Nova 2007, 30, 957964.

3. Xiao, Z.-P.; Xue, J.-Y.; Tan, S.-H.; Li, H.-Q.; Zhu H.-L. Bioorg. Med. Chem. 2007, 15, 4212-4219.

4. Reddy, D. S.; Judd, W. R.; Aubé, J. Org. Lett. 2003, 5, 38993902. 